\title{
Characterization of grain cadmium concentration in indica hybrid rice
}

\author{
Kai WANG ${ }^{1,2,3}$, Qunfeng ZHOU ${ }^{1,3}$, Tianze YAN ${ }^{1,3}$, Shilong XU ${ }^{1,3}$, Longyi ZHAO ${ }^{1,3}$, Weicheng WANG ${ }^{4}$, \\ Zhigang JIN ${ }^{4}$, Peng QIN ${ }^{1,3}$, Chenjian FU ${ }^{1,3}$, Liangbi CHEN $(\bowtie)^{2}$, Yuanzhu YANG $\left.(\bowtie)\right)^{1,2,3}$ \\ 1 Key Laboratory of Southern Rice Innovation \& Improvement, Ministry of Agriculture and Rural Affairs, Yuan Longping High-Tech \\ Agriculture Co., Ltd., Changsha 410000, China \\ 2 Department of Botany, College of Life Sciences, Hunan Normal University, Changsha 410081, China \\ 3 Hunan Engineering Laboratory for Disease and Pest Resistant Rice Breeding, Yahua Seeds Science Academy of Hunan, \\ Changsha 410000, China \\ 4 Seed Management Service Station of Hunan, Changsha 410000, China
}

\begin{abstract}
As a consequence of contamination of soil with heavy metals, cadmium accumulation in grain is of great concern worldwide, but especially in southern China. It is important to evaluate the $\mathrm{Cd}$ accumulation potential of grain before or when examining and approving new cultivars. An evaluation method and criteria for verifying $\mathrm{Cd}$ accumulation potential in rice are proposed, and the $\mathrm{Cd}$ accumulation potential of 56 mid-season indica hybrids collected from the provincial cultivar trials in 2016 were investigated. Genotype, environment and their interactions strongly affected the variation in grain $\mathrm{Cd}$ accumulation. Two hybrids were identified as slightly $\mathrm{Cd}$ accumulating. Hybrids with slight $\mathrm{Cd}$ accumulation potential would be suitable for safe grain production on polluted land (total $\mathrm{Cd}$ under $2.0 \mathrm{mg} \cdot \mathrm{kg}^{-1}$ ) in Hunan Province (China) and should be considered for new cultivar evaluation and approval. This evaluation method and criterion could be applied for certifying $\mathrm{Cd}$ accumulation potential of rice cultivars.
\end{abstract}

Keywords accumulation, cadmium, hybrid, methodology, rice

\section{Introduction}

Cadmium is a toxic trace element belonging to group II B of the periodic table of elements. The long-term exposure to high levels of $\mathrm{Cd}$ poses serious health problems to humans, such as anemia, hypertension, cancer, cardiac failure, cerebrovascular infarction, emphysema, proteinuria, serious lung damage, renal dysfunction, cataract formation in eyes and osteoporosis ${ }^{[1]}$. $\mathrm{Cd}$ in soil and water

Received February 2, 2019; accepted June 13, 2019

Correspondences: chenliangbi@126.com,yzhuyah@163.com can be taken up by certain crops and accumulated in the human body via the food chain ${ }^{[2]}$. Due to the widespread contamination of $\mathrm{Cd}$ in soil, mostly from anthropogenic sources, human exposure occurs mainly from consumption of Cd contaminated food. Food accounts for about $90 \%$ of Cd exposure in the general non-smoking population ${ }^{[3,4]}$. A recent nationwide soil survey in China showed that $7 \%$ of the soil samples were contaminated with $\mathrm{Cd}^{[5]}$. Regional, national and global actions are needed to decrease global environmental $\mathrm{Cd}$ releases and reduce occupational and environmental exposure. A land retirement program in a heavy metal contaminated area has been conducted by the government of China to minimize dietary heavy metal contamination. The Changsha-Zhuzhou-Xiangtan area of Hunan Province, a heavy metal pollution disaster area, was the first regional pilot of the land retirement program and a total of about $6.7 \mathrm{kha}$ of land were fallowed in $2016^{[6]}$.

Rice (Oryza sativa) is a major staple food and can accumulate high concentrations of $\mathrm{Cd}$ in its grain if grown on $\mathrm{Cd}$ polluted soil ${ }^{[7]}$. Hence, it is important to minimize $\mathrm{Cd}$ content in rice. Breeding of low $\mathrm{Cd}$ accumulating rice cultivars could be one of the effective ways to decrease the flux of toxic pollutants into the human food chain without any additional cost. Fortunately, there is considerable natural variation in $\mathrm{Cd}$ accumulation in rice that could be exploited for breeding low Cd accumulating cultivars ${ }^{[8-10]}$. The identification of $\mathrm{Cd}$ accumulation potential of rice can prevent cultivars with high $\mathrm{Cd}$ accumulation potential from being released in $\mathrm{Cd}$ contaminated areas.

Cropping low $\mathrm{Cd}$ accumulating cultivars would be a reasonable option for farmers to cope with the Cd risk and to reduce the influx of pollutants to the human food chain, especially in cases where the soil contamination conditions are unknown. Here, we propose an evaluation method and criteria for assessing $\mathrm{Cd}$ accumulation potential of rice and 
investigated the $\mathrm{Cd}$ accumulation potential of 56 midseason $O$. sativa indica hybrids.

\section{Materials and methods}

\subsection{Plant materials}

A total of 56 mid-season indica hybrids were collected in 2016 from provincial cultivar trials in Hunan Province, China.

\subsection{Soil environment experiment}

The experiments were in four soil-filled concrete tanks (T1, T2, T3 and T4 indicating the soil treatment, see Table 1) at the experimental base of Longping High-Tech (Ningxiang City, Hunan Province, China) in 2016. The soil for each concrete tank was collected from rice paddies polluted with $\mathrm{Cd}$ ranging from slightly polluted $\left(0.25 \mathrm{mg} \cdot \mathrm{kg}^{-1}\right)$ to severely polluted $\left(2.18 \mathrm{mg} \cdot \mathrm{kg}^{-1}\right)$. All hybrids were grown in a randomized complete block design with three replicates in each concrete tank. Seedlings ( $25 \mathrm{~d}$ old $)$ were transplanted in one row of six plants per line at spacing of $17 \mathrm{~cm} \times 27 \mathrm{~cm}$. The experimental tanks were flooded with water to a depth of $2-3 \mathrm{~cm}$ during the vegetative growth phase and about $5 \mathrm{~cm}$ during booting. After full heading, no surface water was maintained, but moisture management was applied through intermittent irrigation such that the soil moisture content was maintained above $70 \%$. Cultivation was conducted in the normal season and according to standard practice. Sowing and transplanting were performed in late May and late June, respectively.

\subsection{Trait evaluation}

Days to heading (DTH) of each plant was recorded and DTH of each line calculated as the mean value for the six plants of that line. Plant samples and fresh soil samples from the top $15 \mathrm{~cm}$ of the soil profile from each tank were collected at harvest. $\mathrm{Cd}$ concentrations of the brown rice grains and hull were determined by atomic absorption spectrophotometry (PerkinElmer 2100, Rodgau, Germany) following $\mathrm{HNO}_{3}-\mathrm{HClO}_{4}$ (4:1) digestion. The standardized analytical methods of China were used (GB/T5009, 151996).

\subsection{Statistical analyses}

Analyses of variances were performed among hybrids for each and across all environments with the PROC GLM procedure (SAS Institute 2012) following the model:

$$
Y=\mu+E+R+G+G E I+e
$$

where $Y=$ observed value of $\mathrm{Cd}$ from each test unit, $\mu=$ population mean, $E=$ environmental effect, $R=$ replication effect within each environment, $G=$ genotype (hybrid) effect, $G E I=$ interaction effect between each genotype and environment, and $e=$ residual effect. The environment and genotype were treated as fixed factors and the replicationwithin-environment was considered to be a random factor. The significance of environmental variance was tested against the replication-within-environment entity.

\subsection{Brown rice $\mathrm{Cd}$ accumulation potential}

Cd accumulation potential of brown rice grain was rated by the standards detailed in Table 2.

\section{Results}

\subsection{Statistical analysis}

As shown in Table 3, the Cd accumulation in the brown rice grain differed significantly $(P<0.001)$ for environment, genotype and $G E I$ with an average $\mathrm{Cd}$ of $0.372 \mathrm{mg} \cdot \mathrm{kg}^{-1}$ that ranged from 0.061 to $1.211 \mathrm{mg} \cdot \mathrm{kg}^{-1}$ across the four environments. The effects of environment (treatment), genotype and GEI contributed $37.6 \%, 34.4 \%$ and $20.9 \%$, respectively, of the total sums of squares to the variation in grain $\mathrm{Cd}$ accumulation. The effects of environment, genotype and $G E I$ all contributed significantly $(P<0.0001)$ to the variation in hull $\mathrm{Cd}$ accumulation and accounted for $21.3 \%, 34.5 \%$ and $33.2 \%$ of the

Table 1 Effect of different treatments on mid-season indica hybrid rice Cd accumulation

\begin{tabular}{|c|c|c|c|c|c|c|c|c|}
\hline \multirow[t]{2}{*}{ Treatment } & \multirow{2}{*}{$\begin{array}{c}\text { Total soil Cd } \\
\text { concentration } \\
/\left(\mathrm{mg} \cdot \mathrm{kg}^{-1}\right)\end{array}$} & \multirow{2}{*}{$\begin{array}{l}\text { Bio-available } \mathrm{Cd} \\
\text { concentration } \\
/\left(\mathrm{mg} \cdot \mathrm{kg}^{-1}\right)\end{array}$} & \multirow[t]{2}{*}{$\mathrm{pH}$} & \multirow[t]{2}{*}{$\begin{array}{l}\text { Total soil organic } \\
\text { matter content } / \%\end{array}$} & \multicolumn{2}{|c|}{$\mathrm{Cd}$ accumulation $/\left(\mathrm{mg} \cdot \mathrm{kg}^{-1}\right)$} & \multicolumn{2}{|c|}{$\begin{array}{l}\text { Percentage of } \\
\text { brown rice Cd } \\
\text { under the limit }\end{array}$} \\
\hline & & & & & Brown rice & Hull & A & B \\
\hline $\mathrm{T} 1$ & 0.25 & 0.11 & 5.87 & 2.61 & $0.092(0.010-0.374)$ & $0.049(0.010-0.124)$ & 94.6 & 100.0 \\
\hline $\mathrm{T} 2$ & 0.59 & 0.25 & 6.11 & 2.93 & $0.269(0.048-0.619)$ & $0.086(0.024-0.245)$ & 37.5 & 83.9 \\
\hline $\mathrm{T} 3$ & 0.97 & 0.49 & 5.79 & 3.39 & $0.446(0.047-1.557)$ & $0.194(0.031-0.855)$ & 26.8 & 58.9 \\
\hline $\mathrm{T} 4$ & 2.18 & 0.95 & 5.95 & 3.17 & $0.779(0.139-2.753)$ & $0.257(0.062-1.258)$ & 3.6 & 21.4 \\
\hline
\end{tabular}

Note: A, the percentage of brown rice samples with Cd lower than the standard of $0.2 \mathrm{mg} \cdot \mathrm{kg}^{-1}$ required by National Food Safety Standard of China (GB2762-2012, NFSSC); B, the percentage of brown rice samples with Cd lower than the standard of $0.4 \mathrm{mg} \cdot \mathrm{kg}^{-1}$ required by FAO/WHO. 
Table 2 Rating standards for $\mathrm{Cd}$ accumulation potential in grain of rice genotypes

\begin{tabular}{lccccc}
\hline \multirow{2}{*}{ Rating } & \multicolumn{3}{c}{ Total soil Cd concentration $/\left(\mathrm{mg} \cdot \mathrm{kg}^{-1}\right), \mathrm{pH} 5.5-6.5$} & Cd accumulation potential \\
\cline { 2 - 4 } & $0.25 \pm 0.05$ & $0.6 \pm 0.05$ & $1.0 \pm 0.1$ & $2.0 \pm 0.2$ & Slight \\
\hline 1 & $<0.2$ & $<0.2$ & $<0.2$ & $<0.2$ & Low \\
2 & $<0.2$ & $<0.2$ & $>0.2$ & $\geqslant 0.2$ & Lower \\
3 & $<0.2$ & $<0.2$ & $\geqslant 0.2$ & $\geqslant 0.2$ & Moderate \\
4 & $<0.2$ & $\geqslant 0.2$ & $\geqslant 0.2$ & $\geqslant 0.2$ & High \\
5 & $\geqslant 0.2$ & & & Undetermined \\
Other & \multicolumn{2}{c}{ Unable to rate } & & \\
\hline
\end{tabular}

Note: The rating is determined by the lowest soil Cd concentration that resulted in grain Cd concentration of $\geqslant 0.2 \mathrm{mg} \cdot \mathrm{kg}^{-1}$ (as indicated in the body of the table).

Table 3 Analysis of variance, including degrees of freedom (df), mean squares (MS), and percent contribution to total sums of squares (SS\%) across five environments for Cd content of grain and hull

\begin{tabular}{|c|c|c|c|c|c|}
\hline \multirow{2}{*}{ Source } & \multirow{2}{*}{$\mathrm{df}$} & \multicolumn{2}{|c|}{ Brown rice } & \multicolumn{2}{|c|}{ Hull } \\
\hline & & MS & $\mathrm{SS} \%$ & MS & $\mathrm{SS} \%$ \\
\hline Environment & 3 & $12.71 * * *$ & 37.62 & $1.42 * * *$ & 21.33 \\
\hline Genotype & 55 & $0.63 * * *$ & 34.38 & $0.13 * * *$ & 34.52 \\
\hline GEI & 165 & $0.13^{* * *}$ & 20.87 & $0.04 * * *$ & 33.24 \\
\hline Rep (environment) & 8 & 0.02 & 0.17 & 0.00 & 0.07 \\
\hline Error & 423 & 0.02 & 6.96 & 0.01 & 10.84 \\
\hline Total & 654 & & & & \\
\hline
\end{tabular}

Note: *** Significant at $P<0.0001$.

total sums of squares, respectively. As expected, the proportions of environment and $G E I$ in the total variation in grain and hull $\mathrm{Cd}$ accumulation were relatively large due to the great differences in $\mathrm{Cd}$ content of the soil environments. This suggests that the hybrids responded differently to the environment in grain and hull $\mathrm{Cd}$ accumulation. Studies of the effect of genotype showed similar effects $(34.4 \%)$ as the environment for variation in grain $\mathrm{Cd}$ accumulation and had major effects $(37.6 \%)$ on variation in hull $\mathrm{Cd}$ accumulation. This result indicates that it is possible to develop rice cultivars with low $\mathrm{Cd}$ accumulation potential through breeding. However, for significantly lower $\mathrm{Cd}$ accumulation potential, more research is needed to better understand the physiological or biochemical mechanisms responsible for $\mathrm{Cd}$ absorption and transportation. In addition, low $\mathrm{Cd}$ accumulating genotypes should be used in breeding programs to develop agronomically suitable cultivars that accumulate low grain $\mathrm{Cd}$ concentration suited to different rice-producing regions.

\subsection{Grain Cd concentration}

The variation in grain $\mathrm{Cd}$ concentration between hybrids was highly significant $(P<0.01)$ at all levels of $\mathrm{Cd}$ exposure (treatments, T1-T4, Table 1). Under low Cd exposure (T1), Cd concentration in the grain ranged from 0.010 to $0.374 \mathrm{mg} \cdot \mathrm{kg}^{-1}$ and averaged $0.092 \mathrm{mg} \cdot \mathrm{kg}^{-1}$.
Under medium $\mathrm{Cd}$ exposure, $\mathrm{Cd}$ concentration in the grain ranged from 0.048 to $0.619 \mathrm{mg} \cdot \mathrm{kg}^{-1}$ with a mean of $0.269 \mathrm{mg} \cdot \mathrm{kg}^{-1}$ for $\mathrm{T} 2$, and from 0.047 to $1.557 \mathrm{mg} \cdot \mathrm{kg}^{-1}$ with a mean of $0.446 \mathrm{mg} \cdot \mathrm{kg}^{-1}$ for T3. Under high Cd exposure (T4), Cd concentration in the grain ranged from 0.139 to $2.753 \mathrm{mg} \cdot \mathrm{kg}^{-1}$ with a mean $0.779 \mathrm{mg} \cdot \mathrm{kg}^{-1}$. This mean was 8.4 times higher than that with low $\mathrm{Cd}$ exposure (Table 1; Table 4). Fifty-three (94.6\%), 21 (37.5\%), 15 $(26.8 \%)$ and $2(3.6 \%)$ of the 56 hybrids of the T1, T2, T3 and $\mathrm{T} 4$ soil environments, respectively, produced brown rice with $\mathrm{Cd}$ concentration under $0.2 \mathrm{mg} \cdot \mathrm{kg}^{-1}$ (safe $\mathrm{Cd}$ limit required by NFSSC, Table 1).

Based on the rating standard of the $\mathrm{Cd}$ accumulation potential of grain of the rice hybrids (Table 2), the tested hybrids were grouped as (1) two slight $\mathrm{Cd}$ accumulating hybrids, (2) 13 low Cd accumulating hybrids, (3) six lower Cd accumulating hybrids, (4) 32 moderate Cd accumulating hybrids, and (5) three high $\mathrm{Cd}$ accumulating hybrids (Table S1). HR46 and HR48 were identified as slight $\mathrm{Cd}$ accumulating hybrids that could be grown for production of Cd safe grain $\left(\mathrm{Cd} \leqslant 0.2 \mathrm{mg} \cdot \mathrm{kg}^{-1}\right)$ in Cd contaminated soils with total $\mathrm{Cd}$ content about $2.0 \mathrm{mg} \cdot \mathrm{kg}^{-1}$.

3.3 Stability of grain $\mathrm{Cd}$ concentrations in different soil environments

As shown in Table 4, the correlation coefficients among grain $\mathrm{Cd}$ concentration in $\mathrm{T} 1, \mathrm{~T} 2, \mathrm{~T} 3$ and $\mathrm{T} 4$ with different 
Table 4 Correlation of $\mathrm{Cd}$ concentration in brown rice between four soil treatments

\begin{tabular}{|c|c|c|c|c|}
\hline Treatment & $\mathrm{T} 1$ & $\mathrm{~T} 2$ & T3 & $\mathrm{T} 4$ \\
\hline $\mathrm{T} 1$ & 1.000 & & & \\
\hline $\mathrm{T} 2$ & $0.750 * * *$ & 1.000 & & \\
\hline $\mathrm{T} 3$ & $0.805^{* * *}$ & $0.923 * * *$ & 1.000 & \\
\hline $\mathrm{T} 4$ & $0.752 * * *$ & $0.744 * * *$ & $0.768 * * *$ & 1.000 \\
\hline
\end{tabular}

Note: *** Significant at $P<0.0001$, see Table 1 for details of treatments T1-T4.

levels of $\mathrm{Cd}$ exposure were all significantly positive $(r=$ 0.744-0.923, $P<0.0001)$. The highest correlation $(r=$ $0.923, P<0.0001)$ was observed between the grain $\mathrm{Cd}$ concentrations of two medium Cd exposure levels (T2 and T3). This result suggests a certain stability and consistency of the genotype response to medium $\mathrm{Cd}$ exposure (especially at about $0.6-1.0 \mathrm{mg} \cdot \mathrm{kg}^{-1}$ ) in terms of grain $\mathrm{Cd}$ accumulation. The two lowest correlations were observed between the grain Cd concentrations in $\mathrm{T} 1$ and $\mathrm{T} 2(r=0.750)$, and between T2 and T4 $(r=0.744)$. These results suggest that the $\mathrm{Cd}$ accumulation potential of a rice genotype is not invariable under different $\mathrm{Cd}$ exposures. That is, a low $\mathrm{Cd}$ accumulating line in low $\mathrm{Cd}$ exposure does not mean it is also low $\mathrm{Cd}$ accumulating when exposed to high levels of $\mathrm{Cd}$, and vice versa. For example, HR31 showed low $\mathrm{Cd}$ accumulation potential (grain $\mathrm{Cd}$ of $0.034 \mathrm{mg} \cdot \mathrm{kg}^{-1}$; ranked eighth lowest Cd concentration) in $\mathrm{T} 2$, but high $\mathrm{Cd}$ accumulation potential (grain $\mathrm{Cd}$ of
$1.219 \mathrm{mg} \cdot \mathrm{kg}^{-1}$, and ranked fifth highest $\mathrm{Cd}$ concentration) in T4. Differences in the active uptake and passive uptake of $\mathrm{Cd}$ accumulation in different rice lines might be the main reason for the variability of $\mathrm{Cd}$ accumulation potential at different levels of $\mathrm{Cd}$ exposure. It is necessary that multiple trials with different levels of $\mathrm{Cd}$ exposure should be performed to evaluate the $\mathrm{Cd}$ accumulation potential of rice genotypes.

\subsection{Relationship between grain Cd concentration and DTH,} hull $\mathrm{Cd}$ concentration

The Relationship between grain $\mathrm{Cd}$ concentration and DTH was showed in Fig. 1. There was a significant positive correlation $(P<0.0001)$ between $\mathrm{Cd}$ concentration and DTH. The correlation coefficients were 0.705 , $0.828,0.845$ and 0.747 in T1, T2, T3 and T4, respectively (Fig. 1). The highest correlations were found under
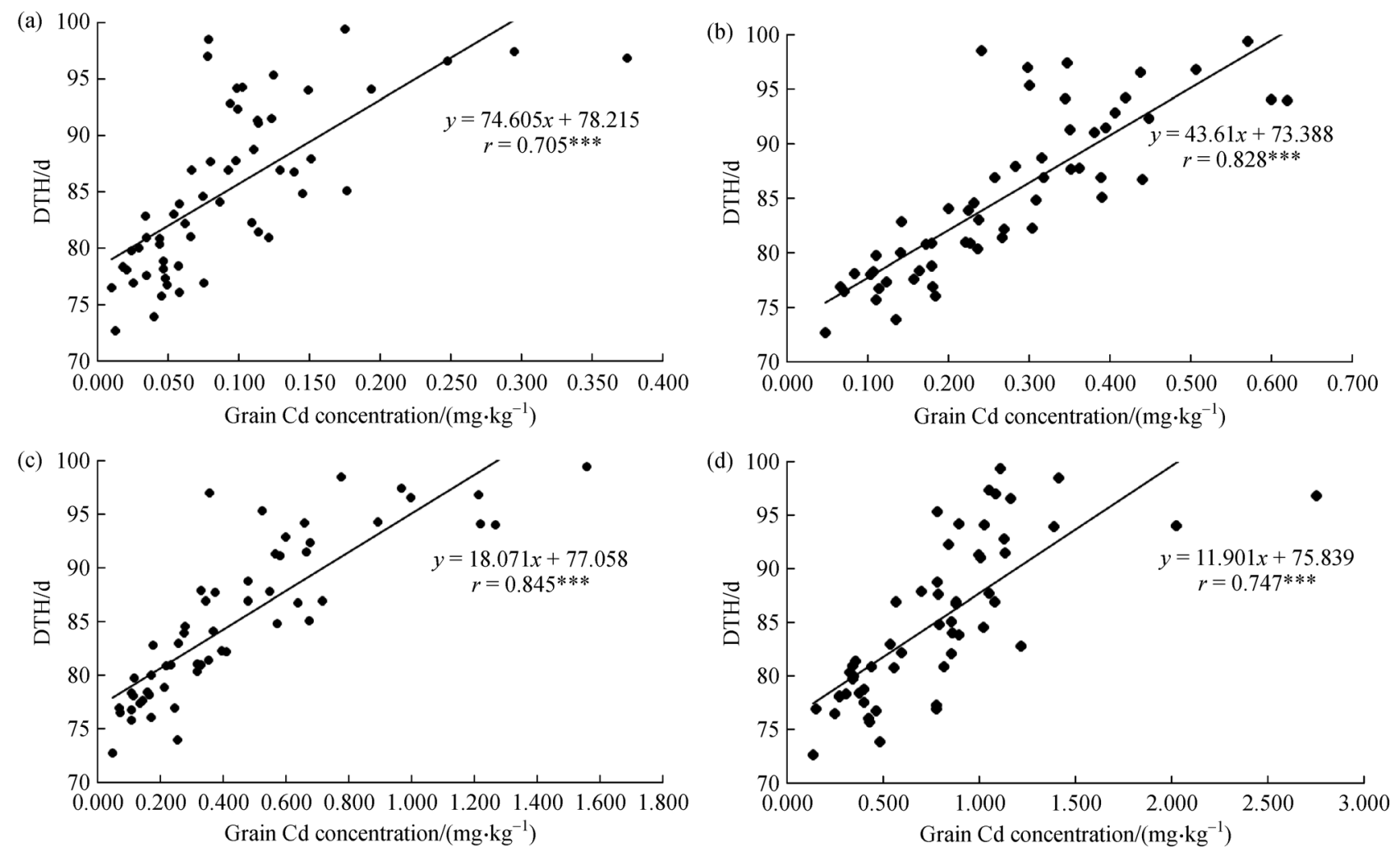

Fig. 1 Correlation between grain Cd concentration and days to heading (DTH) in T1 (a), T2 (b), T3 (c) and T4 (d) (see Table 1 for details of treatments T1-T4). ${ }^{* * *}$ Significant at $P<0.0001$. 
medium Cd exposure (T2 with $0.59 \mathrm{mg} \cdot \mathrm{kg}^{-1}$ and $\mathrm{T} 3$ with $0.97 \mathrm{mg} \cdot \mathrm{kg}^{-1}$ ). These results indicate that the line with the longer growth period accumulates more $\mathrm{Cd}$ in grains, especially when was cropped in the polluted soil with $\mathrm{Cd}$ ranging from about 0.60 to $1.00 \mathrm{mg} \cdot \mathrm{kg}^{-1}$. Only two hybrids, those with the shortest $\mathrm{DTH}$, produced $\mathrm{Cd}$ pollution-safe grains $\left(\mathrm{Cd}<0.2 \mathrm{mg} \cdot \mathrm{kg}^{-1}\right)$ under high $\mathrm{Cd}$ exposure (T4). The Relationship between grain $\mathrm{Cd}$ concentration and hull $\mathrm{Cd}$ concentration was showed in Fig. 2. A significant positive correlation $(P<0.01$ or $P<0.0001)$ was observed between grain and hull $\mathrm{Cd}$ concentrations. The correlation coefficients were 0.369 , $0.658,0.711$ and 0.798 in the T1, T2, T3 and T4, respectively (Fig. 2). It is noteworthy that the correlation between grain $\mathrm{Cd}$ concentration and hull $\mathrm{Cd}$ concentration increased with soil $\mathrm{Cd}$ exposure.

\section{Discussion}

$\mathrm{Cd}$ is a toxic heavy metal, which is known as one of the major environmental pollutants that harms human health ${ }^{[1]}$. Cd minimization must be an important requirement in rice cropping, especially in areas subject to industrial pollution. It is necessary to evaluate the $\mathrm{Cd}$ accumulation potential of new cultivars using reliable assessment methods before cultivar approval and promotion. There have been many studies on the characterization of grain $\mathrm{Cd}$ concentration in rice ${ }^{[9,11,12]}$. However, most of these studies were implemented in limited environments or in random $\mathrm{Cd}$ contaminated field experiments, and the evaluation methods were mostly not suitable to reliably characterize $\mathrm{Cd}$ accumulation potential of rice at different levels of $\mathrm{Cd}$ contamination of soil. An evaluation method and criteria for verifying rice $\mathrm{Cd}$ accumulation potential are proposed, and these were applied to 56 tested hybrids collected from the regional trial of new cultivars in Hunan Province. The effects of genotype and GEI contributed $34.4 \%$ and $20.9 \%$ of the grain Cd accumulation variation in four environments from slightly polluted $\left(0.25 \mathrm{mg} \cdot \mathrm{kg}^{-1}\right)$ to severely polluted $\left(2.18 \mathrm{mg} \cdot \mathrm{kg}^{-1}\right)$. This indicates that it is possible to develop rice cultivars with low $\mathrm{Cd}$ accumulation potential through breeding.

Based on our evaluation method and criteria two hybrids (HR46 and HR48) were identified as slight Cd accumulating hybrids. In theory, HR46 and HR48 can be grown in the most of the Cd polluted soil in Hunan Province (China) to give grain $\mathrm{Cd}$ concentrations under $2.0 \mathrm{mg} \cdot \mathrm{kg}^{-1}$. However, $62.5 \%$ of the tested hybrids were found to be moderate to high $\mathrm{Cd}$ accumulating cultivar. Given the risk of grain Cd accumulation, HR21, HR26 and HR36, identified as having high $\mathrm{Cd}$ accumulation potential,
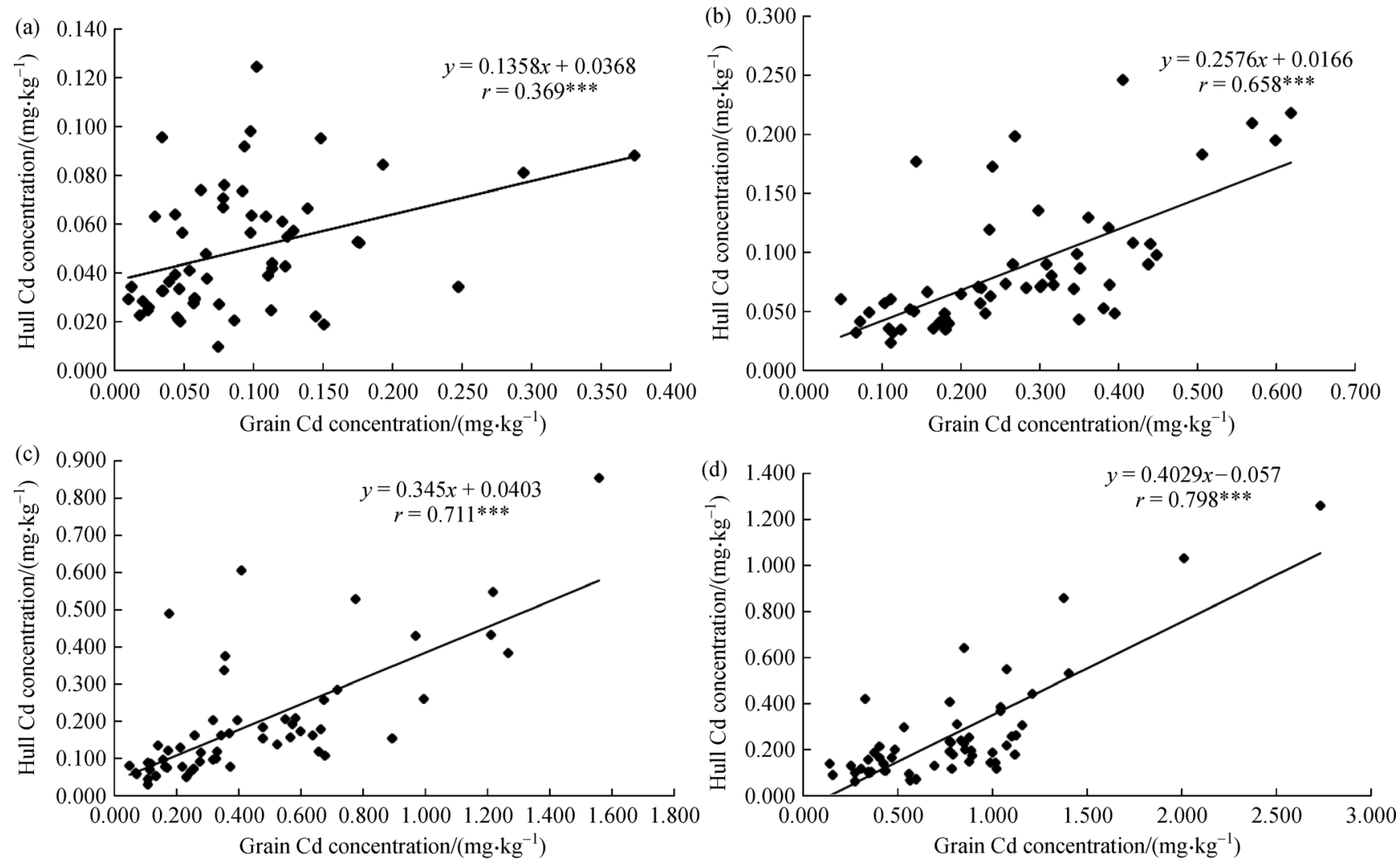

Fig. 2 Correlation between grain and hull Cd concentration in T1 (a), T2 (b), T3 (c) and T4 (d) (see Table 1 for details of treatments T1T4). *** Significant at $P<0.0001$. 
should not be released to seed markets. These results also indicate that it is possible to develop a cultivar that can produce $\mathrm{Cd}$ safe grains even in $\mathrm{Cd}$ polluted soil, as long as the soil has a Cd contamination of under $2.0 \mathrm{mg} \cdot \mathrm{kg}^{-1}$ and with normal soil $\mathrm{pH}$ (about $\mathrm{pH}$ 6). This is the first study to investigate the grain $\mathrm{Cd}$ accumulation potential of rice using this kind of experimental design and rating standard.

Correlation analysis of grain $\mathrm{Cd}$ concentration of hybrids across $\mathrm{Cd}$ contamination levels was used to assess the stability of our evaluation method and criteria for verifying rice $\mathrm{Cd}$ accumulation potential. The correlations were high, with $r=0.774-0.923(P<0.0001)$ across four $\mathrm{Cd}$ contamination levels with $\mathrm{Cd}$ exposure from slightly polluted $\left(0.25 \mathrm{mg} \cdot \mathrm{kg}^{-1}\right)$ to severely polluted $\left(2.18 \mathrm{mg} \cdot \mathrm{kg}^{-1}\right)$. This is higher than that in the study of Duan et al. ${ }^{[1]}$ using five experiments at three field sites across two years with $\mathrm{Cd}$ exposure of $0.5-1.4 \mathrm{mg} \cdot \mathrm{kg}^{-1}$. This evaluation method for verifying rice $\mathrm{Cd}$ accumulation potential is more stable than with experiments in field sites.

Significant positive correlations $(P<0.0001)$ between $\mathrm{Cd}$ concentration and DTH were found in this study. The two slight $\mathrm{Cd}$ accumulating hybrids had the shortest DTH. Similarly, Duan et al. ${ }^{[11]}$ found that later flowering hybrids accumulated significantly higher $\mathrm{Cd}$ in grain than earlier flowering hybrids. Several other studies also detected a correlation between grain Cd concentrations and DTH, but there is no consistent agreement. Ishikawa et al. ${ }^{[13]}$ found the grain $\mathrm{Cd}$ concentrations were negatively correlated with DTH. Sun et al. ${ }^{[10]}$ did not detect a strong correlation between grain $\mathrm{Cd}$ concentration and heading date, and suggested that the breeding of rice with low grain $\mathrm{Cd}$ level should not be subjected to the limitation of heading date. These divergent results might be attributable to genetic linkage inheritance of grain $\mathrm{Cd}$ content and flowering time. Abe et al. ${ }^{[14]}$ reported a grain Cd content QTL $q l G C d 3$ that mapped within the $3.5-\mathrm{Mb}$ region and is collocated with flowering time gene $H d 6$. The water management difference of the paddy, especially after heading, could be a contributing factor. It is well known that intermittent flooding irrigation management of paddy soil reduces $\mathrm{Cd}$ bioavailability and greatly decreased the $\mathrm{Cd}$ concentrations in grain ${ }^{[8,15,16]}$. To further reduce the water management impact on $\mathrm{Cd}$ accumulation potential evaluation, our evaluation method was further improved in 2017 by (1) designing and fitting rain shelters to reduce the impact of rain, especially rain during the grain filling period, and (2) conducting experiments separately for early, middle and late heading genotypes to allow paddy water management to be tailored according to heading time.

\section{Conclusions}

This study proposes an evaluation method and criteria for verifying rice $\mathrm{Cd}$ accumulation potential. Measuring the $\mathrm{Cd}$ accumulation potential of hybrids revealed that genotype and environment explained a total of $72 \%$ of the variation in grain $\mathrm{Cd}$ accumulation. Fifty-six rice hybrids were evaluated and rated for $\mathrm{Cd}$ accumulation potential in grain according to our proposed evaluation method and criteria. Two slight $\mathrm{Cd}$ accumulating hybrids and three high $\mathrm{Cd}$ accumulating hybrids were identified. There was a significant positive correlation between grain $\mathrm{Cd}$ concentration and DTH, especially under medium levels of $\mathrm{Cd}$ exposure.

Supplementary materials The online version of this article at https:/doi. org/10.15302/J-FASE-2019281 contains supplementary material (Table S1).

Acknowledgements This research was supported by grants from the National Key Technology Research and Development Program of China (2016YFD0101801), the Rice Cadmium Accumulation Characteristics Identification Project of the Seed Management Service Station of Hunan, Special Project of National Independent Innovation Demonstration Zone (2018XK2005) and Science and Technology Innovation Program (2018NK1020).

Compliance with ethics guidelines Kai Wang, Qunfeng Zhou, Tianze Yan, Shilong Xu, Longyi Zhao, Weicheng Wang, Zhigang Jin, Peng Qin, Chenjian $\mathrm{Fu}$, Liangbi Chen, and Yuanzhu Yang declare that they have no conflicts of interest or financial conflicts to disclose.

This article does not contain any studies with human or animal subjects performed by any of the authors.

\section{References}

1. Sebastian A, Prasad M N V. Cadmium minimization in rice. A review. Agronomy for Sustainable Development, 2014, 34(1): 155173

2. World Health Organization. Health risks of heavy metals from long range trans-boundary air pollution. Copenhagen: World Health Organization Regional Office for Europe, 2007, 40-45

3. Clemens S, Aarts M G, Thomine S, Verbruggen N. Plant science: the key to preventing slow cadmium poisoning. Trends in Plant Science, 2013, 18(2): 92-99

4. World Health Organization. Exposure to cadmium: a major public health concern. Preventing Disease Through Healthy Environments, 2010, 3-6

5. Ministry of Environmental Protection. The Ministry of Land and Resources Report on the national soil contamination survey. 2014

6. Ministry of Agriculture. A pilot plan to carry out arable rotation and fallow. 2016

7. Uraguchi S, Fujiwara T. Cadmium transport and tolerance in rice: perspectives for reducing grain cadmium accumulation. Rice, 2012, 5(1): 5

8. Arao T, Ae N. Genotypic variations in cadmium levels of rice grain. Soil Science and Plant Nutrition, 2003, 49(4): 473-479

9. Jiang S, Shi C, Wu J. Genotypic differences in arsenic, mercury, lead and cadmium in milled rice (Oryza sativa L.). International Journal of Food Sciences and Nutrition, 2012, 63(4): 468-475

10. Sun L, Xu X, Jiang Y, Zhu Q, Yang F, Zhou J, Yang Y, Huang Z, Li A, Chen L, Tang W, Zhang G, Wang J, Xiao G, Huang D, Chen C. Genetic diversity, rather than cultivar type, determines relative grain Cd accumulation in hybrid rice. Frontiers of Plant Science, 2016, 7: 
1407

11. Duan G, Shao G, Tang Z, Chen H, Wang B, Tang Z, Yang Y, Liu Y, Zhao F J. Genotypic and environmental variations in grain cadmium and arsenic concentrations among a panel of high yielding rice cultivars. Rice, 2017, 10(1): 9

12. Yu H, Wang J, Fang W, Yuan J, Yang Z. Cadmium accumulation in different rice cultivars and screening for pollution-safe cultivars of rice. Science of the Total Environment, 2006, 370(2-3): 302-309

13. Ishikawa $S, A e N$, Yano M. Chromosomal regions with quantitative trait loci controlling cadmium concentration in brown rice (Oryza sativa). New Phytologist, 2005, 168(2): 345-350

14. Abe T, Nonoue Y, Ono N, Omoteno M, Kuramata M, Fukuoka S,
Yamamoto T, Yano M, Ishikawa S. Detection of QTLs to reduce cadmium content in rice grains using LAC23/Koshihikari chromosome segment substitution lines. Breeding Science, 2013, 63(3): 284-291

15. Arao T, Kawasaki A, Baba K, Mori S, Matsumoto S. Effects of water management on cadmium and arsenic accumulation and dimethylarsinic acid concentrations in Japanese rice. Environmental Science \& Technology, 2009, 43(24): 9361-9367

16. Hu P, Huang J, Ouyang Y, Wu L, Song J, Wang S, Li Z, Han C, Zhou L, Huang Y, Luo Y, Christie P. Water management affects arsenic and cadmium accumulation in different rice cultivars. Environmental Geochemistry and Health, 2013, 35(6): 767-778 